\title{
Appraisal Of Ethical Performance: A Theoretical Model
}

T. T. Selvarajan, University of Houston-Victoria, USA Ron Sardessai, University of Houston-Victoria, USA

\begin{abstract}
Ethical behavior of organizational members has been the subject of considerable interest during the past decade both among practitioners and academics. However, performance appraisal systems, for the most part, have exclusively concentrated on business performance to the exclusion of ethical dimensions of job performance. Given the increasing importance of ethical issues in organizations, there is a need to correct this aberration in the current approach to appraisal system development and include ethical dimensions in the performance appraisal domain. As a first step to the inclusion of ethical dimensions to the job performance, we propose a cognitive model for appraisal ethical performance in organizations. The performance appraisal literature based on the cognitive processing paradigm (e.g., Landy and Farr, 1980) provides a rich theoretical foundation for studying ethical judgment process. Specifically, the cognitive approach describes how the performance judgment process is influenced by schematic, attributional and affective influences when processing ratee performance information.
\end{abstract}

Keywords: Appraisal of ethical performance, Cognitive Processing Model

\section{INTRODUCTION}

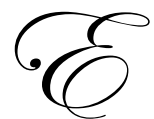

thical behavior at the organizational and individual level has been of considerable interest to researchers for the past two decades (e.g., Baumhart, 1961; Brenner \& Mohlander, 1977). Ethics in business has been asserted to be the most important problem facing American companies today. The issue of ethics has recently become the focus of media attention in the wake of scandals in companies such as Enron, WorldCom, and Tyco International. In addition to being a current issue in the media domain, unethical behavior in organizations has also been identified as a relevant social issue demanding the attention of researchers. The recent attention on ethics among practitioners and researchers underscores the need for improved ethics in organizations. We believe that employee performance appraisal and management systems can play a critical role in improving ethical conduct of employees in organizations. Explicit incorporation of ethical behavior into performance appraisal has been recently recommended by researchers (Buckley, 2001; Weaver, 2001; Weaver \& Trevino, 1999). Their argument is that inclusion of ethical dimensions in regular performance appraisal systems integrates ethics expectations into employees' formal role identities and makes ethical conduct at work relevant and rewarding for employees. However, most of the research on ethics has not directly addressed ethical performance and its measurement. Rather, research has either been prescriptive or focused on surveys regarding perceptions or opinions of ethical performance. Further, theoretical work has consisted of the development of models of the determinants of ethical behavior (e.g., Trevino, 1986). In general, these models all propose that personal and organizational variables influence ethical behavior (Akaah \& Lund, 1994). In a conceptual consideration, Gatewood \& Carroll (1991) identify the direct measurement of ethical behavior as necessary for the advancement of the study of ethics. No doubt, understanding the psychological and situational determinants of ethical performance is important. However, the accurate measurement of ethical behavior is important as well.

Unethical behavior among organizational members can take a variety of forms, ranging from breaking civil or criminal law to disregarding company policies. Some instances of unethical behavior may result in objective evidence that unethical behavior occurred. However, just as with the assessment of job performance (Cardy \& Dobbins, 1994), determination of the level of ethical performance requires subjective judgments. Given the 
importance of accurate measurement of ethical performance in organizations, investigation of the levels of accuracy of ethical performance judgments and influences on the accuracy of these judgments is needed. The objective of this study is to apply the methodology commonly used in the appraisal literature and develop a model for appraising ethical performance of employees. We discuss the model below and offer theoretical propositions that can be empirically tested.

\section{APPRAISAL OF ETHICAL PERFORMANCE: A COGNITIVE PROCESS MODEL}

The field of performance appraisal offers a rich set of paradigms and measurement techniques that can be applied to the study of ethical performance appraisal. At a very basic level, performance ratings can be influenced by three types of information: behavior, outcomes and traits. Indeed, research has found that performance ratings are significantly influenced by ratee behavior, outcomes and rater trait inferences (Cardy, Anderson and Evans, 1991). Research in performance appraisal has shifted from an emphasis on formats to an emphasis on rater cognitive information processing (Cardy \& Dobbins, 1994). A model of ethical performance judgment processes based on the cognitive processing model is presented in figure below.

\section{Appraisal Of Ethical Performance: A Cognitive Process Model}

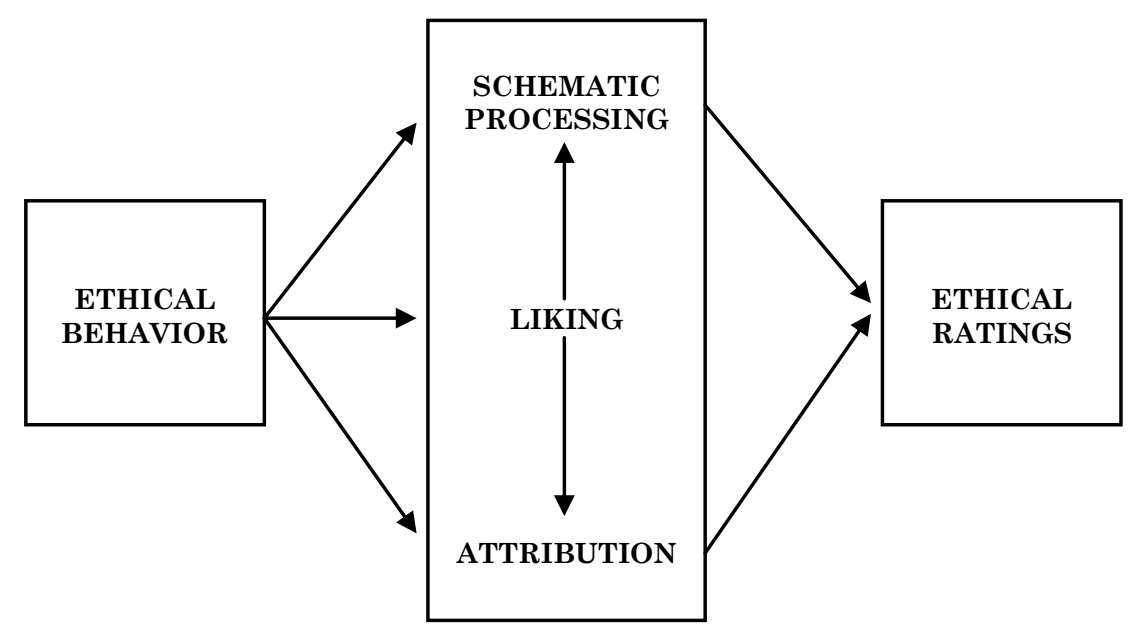

A basic assumption in this model is that ethical performance cues occur in conjunction with job performance cues. Job performance can be defined as the level of effectiveness on dimensions generated with typical job analysis approaches and measured by traditional appraisal systems. Examples of performance dimensions for a salesperson position are sales ability, product knowledge, customer orientation, innovativeness etc. Ethical performance deals with process dimensions that reflect how the performance dimensions are carried out in terms of moral and legal values. Examples of ethical dimensions for a salesperson position are deception, falsification, padding expense account, bribery etc. As shown in the model, ethical performance cues and job performance cues influence each other. The possibility that ethical performance judgments are influenced by job performance dimensions was shown in a study by Cardy and Selvarajan (2004a). Their study demonstrated that outcomes (job performance) biased ethical judgments. Specifically, it was found that successful people were judged as more ethical than warranted. A natural corollary for the outcome effect on ethical judgment hypothesis would be that job performance ratings are influenced by the ethicalness of ratee behaviors. This proposition has not been tested and will be tested as a part of this study.

The performance appraisal literature has demonstrated that appraisal judgments can be influenced by at least three processes: schematic, liking and attribution (Cardy and Dobbins, 1994). It can be expected these processes can influence ethical performance judgment too. Just as with performance judgments, it seems reasonable to expect ethical judgments to be a function of these three processes. In addition, liking may affect performance and 
ethical ratings through attribution and schematic processing (Cardy and Dobbins, 1994). Thus, liking may affect ethical ratings directly and through schematic and attributional processes. In sum, the model proposes that ethical cues and job performance cues interact with each other and influence the three judgment processes. The resultant ethical and job performance ratings would be a function of the three judgment processes (schematic, liking and attribution). The possible operation of each the three processes on ethical judgments will next be explored.

\section{Performance appraisal and schematic processing}

Research in social cognition (e.g., Fiske and Taylor, 1991) suggests that people are guided by a two stage process when processing information about others. First, people categorize others based on the extent to which individuals match the prototypical characteristics of a category (Rosch, 1978). Second, once people are categorized, further information processing is guided by schemas. Schemas are knowledge structures that represent assumptions and beliefs associated with categories. These assumptions and beliefs influence acquisition, storage and recall of information about others. In a performance appraisal setting, schematic processing means that raters process information based on their schemas for ratees and not on actual observed behaviors (Feldman, 1981). For example, raters may categorize ratees as good or poor performers and further information processing and judgments would be based on the schemas for a good or a poor performer. If, for example, a ratee is categorized as a good performer, raters tend to attend to, store and recall information consistent with the prototype behaviors for a good performer. That is, they may ignore, forget or discount information that is inconsistent with the initial categorization.

Schematic processing may also bias rater judgments in an ethical performance appraisal context. Research has shown that performance ratings are significantly influenced by ratee behavior, outcomes and rater trait inferences (Cardy, Anderson and Evans, 1991). A fundamental issue of interest here is the influence of outcomes on performance ratings. Research in this area suggests that outcomes heavily influence performance ratings (DeNisi and Stevens, 1981; Cardy et.al 1991). From a schematic perspective (e.g., Neisser, 1967), a worker who achieves excellent work outcomes may be placed in a high performance cognitive category by the rater. The issue of outcomes affecting ratings is all the more important in appraising ethical performance since this addresses the "means vs ends" dilemma in judging ethical behavior. From a schematic processing perspective, an outcome schema may have an influence on evaluating a person as ethical/unethical. For example, when raters encounter a high performer, he/she may ignore, discount or reinterpret unethical behaviors of the successful ratee to be consistent with the outcome schema. The result would be inordinately positive judgments of the worker's ethical performance. In other words, people may tend to rate the ethics of a successful employee more favorably than that of an unsuccessful employee.

In addition to the influence of outcomes on ethical ratings, it would also be interesting to test the influence of ethical performance on performance ratings. It may be expected that the ethical behavior exhibited by the ratee may have an influence on performance ratings. Similar to the 'outcome schema', an 'ethical schema' may bias performance ratings of the ratee. It may be expected that raters may rate an ethical ratee more favorably in rating his/her job performance and vice versa. The above discussion leads to the following proposition:

Proposition 1a: Outcomes (success/failure) will bias the ethical judgments of raters such that successful ratees would be judged with more positive bias than unsuccessful ratees.

Proposition 1a above was tested in a laboratory study by Cardy and Selvarajan (1997). They found that successful ratees were judged with more positive bias in their ethical ratings than unsuccessful ratees. The present study includes this hypothesis for two reasons. First, this study is a larger study that includes other processes such as liking and attribution. Thus, relative influence of the three processes (schematic, liking and attribution) can be examined. Second, the earlier study used ratee vignettes with all critical incidents for "ethical" ratee representing unethical behavior and vice versa. This portrayal is ratees may be extreme and thus may not reflect actual ratee behaviors found in real life. To present a more realistic picture of ratee behaviors, this study will describe ratee ethical behavior using critical incidents drawn from ethical, unethical and neutral behaviors. For example, an "ethical" ratee will be described using six incidents of ethical behavior, 2 incidents of neutral behavior and 2 incidents of unethical behavior. Similarly, an "unethical" ratee will be described using six incidents of unethical behavior, 2 incidents of neutral behavior and 2 incidents of ethical behavior. 
Observational judgments of performance have been found to be influenced by the level of ratee performance (Gordon, 1970). Specifically, high performers have been found to be rated more accurately than low performers. While the underlying basis for this effect is unclear, it appears that we may give low performers the "benefit of doubt" (Gordon, 1970) and report the occurrence of effective behaviors even though they did not occur. The possibility that a similar phenomenon may occur with the ethical judgment process was examined by Cardy and Selvarajan (1997). They hypothesized that ethical judgments would be more accurate (that is, less biased) for ethical than for unethical ratees. The results, contrary to this hypothesis, indicated that ethical ratees were rated less accurately than unethical ratees. They interpreted the findings in terms of accuracy measures employed. Gordon (1970) employed a measure of hit rates and correct rejection ratees. Indeed, when Baker and Schuck (1975) reanalyzed Gordon's data from a signal detection perspective, they found no consistent evidence for the differential accuracy phenomenon. This study proposes to examine the differential accuracy phenomenon in both ethical performance judgment and job performance judgment domains. Even though the reasons behind the occurrence of this phenomenon are not clear, it would be interesting to examine if there is any difference in the differential accuracy phenomenon for these domains. From the previous studies, it can be expected that the differential accuracy phenomenon will occur for the job performance domain and not for the ethical performance domain. The following proposition is offered:

Proposition 1b: The Differential Accuracy phenomenon will be present in job performance judgments but not in ethical performance judgments.

Any influence on ethical judgment may be moderated by rater differences in ethical beliefs. That is, raters may differ in their internal standards for identifying an issue as ethical/unethical based on their personal beliefs about ethics and the strength of these beliefs may moderate the relationship between outcomes and ethical judgment bias. It is quite possible that raters with strong ethical beliefs may be less biased by outcomes in their ratings. The earlier study by Cardy and Selvarajan (1997) did not find any significant difference based on individual differences as measured by an ethical beliefs scale developed by Froelich and Kottke (1991). This may be because the scale measured just two dimensions ("company support" and "lie to protect the company") and thus may be measuring too narrow of a domain of ethical beliefs. The present study will attempt to study the moderating influence of individual ethical beliefs with a more comprehensive scale developed by Daniel, Elliott-Howard, and DuFrene (1997). They developed a 46-item scale that included five dimensions of ethical performance. The dimensions were personal integrity issues, corporate integrity issues, individual rights issues, environmental issues, and international issues. It is expected that the moderating effects would be more apparent with this more comprehensive scale. Thus, the following hypothesis is offered:

Proposition 2 Individual differences in ethical beliefs will moderate the effect of outcomes on the accuracy of ethical performance judgments.

\section{Attributions and ethical performance judgments}

Causal attributions affect judgments and behavior. Attribution researchers have shown that outcomes in an achievement-related context are often attributed to one of the four sources: ability, effort, task difficulty or luck (Weiner et al 1971; Jones and Nisbett, 1971). In the performance appraisal setting, it has been shown that attributions made on the basis of effort result in more extreme evaluations than ability attributions (Knowlton and Mitchell, 1980). In other words, laziness can lead to lower evaluations than incompetence and hard work can lead to higher evaluations than competence, other things being equal. The four sources mentioned above can be classified on the basis of locus of control (Weiner et. al 1971). Locus of control is external when the cause is not within the control of the actor and internal when the cause is within the control of the actor. Locus of control can be an important determinant of social judgments (Weiner, 1993). For example, a person suffering from AIDS due to promiscuity will be judged as a sinner (internal locus of control) whereas, a person suffering from AIDS due to infectious blood transfusion will be judged as someone unfortunate (external locus of control). Causal attributions also influence the follow up behavior. Research in this area has shown that managers respond more harshly and punitively toward subordinates when they attribute poor performance to internal factors rather than to external factors (e.g., Mitchell, Green and Wood, 1981; Mitchell and Wood, 1980). In a social setting, people who are seen as cause for an unfortunate situation (e.g., obesity due to overeating, lack of exercise) are viewed less 
sympathetically when compared to attributions made to situational factors (e.g., obesity due to thyroid malfunctioning). Further, attribution theory has been applied to overcome self-serving attributional biases (Noel et.al 1987). Noel et.al found that performance of failing students improved when students were exposed to information that suggested that performance is caused by internal, controllable factors such as effort and motivation.

In summary, raters' attributions of ratee performance affect the performance appraisal process. An important effect of causal attributions is that they bias judgment. Managers respond more negatively when they attribute poor performance to internal factors rather than to external factors. In the domain of ethical performance judgments it can be expected that ratees exhibiting unethical behavior may be rated more positively if the cause is attributed to external causes (e.g., supervisory pressure) rather than internal causes. Similarly, ethical performance attributed to internal causes will be rated more positively compared to external attributions. The above discussion leads to the following proposition:

Proposition 3: Causal attribution will mediate the relationship between ethical performance and ethical rating accuracy.

\section{Liking and ethical ratings: The mediating influence of schematic and attributional processes}

Cognitive models of appraisal have considered the influence of affect in the cognitive processing of raters (e.g., Cardy and Dobbins, 1994, 1986 Robbins and DeNisi 1994; Varma, DeNisi and Peters, 1996). Affect in performance appraisal has been categorized as being either undifferentiated or differentiated (Park, Sims and Motowildo, 1987). Though undifferentiated affect (e.g., mood) has been demonstrated to influence a variety of judgments (Isen and Baron, 1991), differentiated affect (e.g., liking) may have the most influence on performance appraisal since it consists of stimulus specific judgments (Cardy and Dobbins, 1994).

Rater liking has been found to underlie the effects of ratee impression management on rater evaluation (Judge and Ferris, 1993) and has been found to be difficult for raters to separate from their assessment of ratee performance (Cardy and Dobbins, 1986). Cardy and Dobbins (1994) observed that liking can influence performance ratings through three mediating processes: direct perception, schematic processing and attribution. Cardy and Dobbins (1986) first demonstrated that liking is integral to performance; that is liking influences performance ratings at a direct perceptual level. The possibility that liking influences performance ratings through the mediating influence of schematic processing has been shown in a number of empirical studies (e.g., Robbins and DeNisi, 1993; Varma, DeNisi, and Peters, 1993; Caranikas-Walkar, 1994). The mediating effect of attributional processes has been shown in empirical studies by Dobbins and Russel (1986) and Mitchell and Wood (1980). Whatever the type of mediating processes, it is apparent that liking can be an important mediator that affects performance ratings. In the field of ethical performance ratings, liking has the potential to mediate the relationship between ethicalness of ratee behavior and ethical ratings. For example, a ratee exhibiting ethical/unethical behavior may be rated as more ethical than warranted because of rater liking for the ratee. Similarly, a ratee exhibiting ethical/unethical behavior may be rated as less ethical than warranted because of rater dislike for the ratee.

As mentioned above, a liking effect on performance ratings may operate through schematic and attributional processes (Cardy and Dobbins, 1994). Liking may bias schema formation and operation. Since liking can be a quick response to a stimulus (Zajonc, 1980), it can influence schematic processing at a very early stage. Fiske and Beattie (1981) have suggested that schemas can be affect-laden and affect-laden schemas may influence all stages of schematic processing. Liking may selectively influence what is attended to, what is recalled and how the rater evaluates. A schematic basis for the influence of liking should have an impact on both observational and evaluation accuracy levels. That is, both the recall of specific incidents of performance and supervisor performance ratings should be affected by liking if its mode of influence is schematic.

In a lab study, Robbins and DeNisi(1993) found that disliked performers are rated as poor performers and liked performed as high performers. They also found that raters ignore affect inconsistent information because it does not fit in with the original categorization of ratee. This suggests the possibility that a rater's schema for a ratee is affect laden. In this study, it appears that a liked schema preempts attention and encoding of information that is inconsistent with the original impression of the ratee. In another study, Varma et.al (1993) found that affect 
significantly influenced ratings. Specifically, they found that the affective influence was stronger for those who kept a diary than those who did not maintain diary. Since raters might have tended to record information consistent with their affect-laden schema, the diary keeping may have helped them to recall schema-laden impressions.

Schoel et.al (1993) found that perceptual processes mediated the relationship between liking and ratings at the behavioral dimension level. A schematic basis for a liking influence should affect both observational and evaluation accuracy. Both these accuracies are important to determine the schematic mechanisms. Observational accuracy is an indicator of rater capability to accurately recall ratee behaviors. This can be tested by using the signal detection theory (Lord, 1985). Liking influences observational accuracy since a liking-biased schema may affect the recall of specific behavioral incidents. Specifically, a liking-biased schema will have high hit rates and high false alarm rates for items consistent with the rater's impression.

Evaluation accuracy is the accuracy with which a rater assesses the worth of ratee performance. Evaluation accuracy may be affected by poor observational accuracy. Evaluation accuracy may also be affected independent of observational accuracy. For example, a correct schema would lead to greater evaluation accuracy regardless of rater's capability to reject false alarm items. Carey (1996) and Caranikas-Walkar (1994) have found further support for the schematic influence of liking. Caranikas-Walkar found some support for the mediating influences of schematic processes. Specifically, she found that liking affected behavioral accuracy. Carey (1997) found that liking influences both observational and evaluative accuracy which suggests that liking affects performance via schematic processing.

Extending this research to the ethical performance domain, liking may influence ethical ratings through the mediating influence of schematic processing. That is, a liked ratee may be categorized as more ethical and a disliked ratee may be categorized as less ethical. In other words, a liked ratee may receive a more positive bias compared to disliked ratee. The above discussion leads to the following proposition:

Proposition 4: The influence of liking on ethical ratings will be mediated by schematic processing.

\section{Liking and ethical ratings: Attributional process as a mediator}

Traditional orientations of attribution theory have taken a cold approach. That is, the possibility that the causal schema may be affect laden has not been widely suggested. Regan et.al (1974) demonstrated that high performance was attributed to internal factors when ratees are liked than when the ratees are disliked. In another study, Regan et.al., found that an actor's helping behavior was more attributed to internal factors when ratees were liked than when they were disliked.

An affect laden causal schema may be an important mechanism in performance appraisal. For example, a supervisor will attribute the poor performance of a liked subordinate to external factors such as task difficulty or bad luck even when evidence points to person responsibility (i.e., distinctiveness, consensus and consistency conditions). Dobbins and Russell (1986) found that supervisors attributed poor performance to internal factors when a subordinate was disliked than when subordinate was liked. This contradicts the suggestions from the "cold" attribution perspective that suggests that people attribute poor performance to an actor's internal factors. Liking does appear to moderate the causal attribution process. In other words, an affective state such as liking may alter the structure of the causal schema of an observer. Mitchell and Wood (1980) found impression management of ratees to be an important moderating variable in the causal attribution process of raters. In sum, there is some evidence that liking may influence causal attributions. Extending these research ideas to ethical performance appraisal, it can be hypothesized that the influence of liking on ethical judgments will, at least in part, operate through a causal attribution process. Specifically, it can be expected that a liked but unethical ratee would receive a more positive ethical rating because the rater may attribute unethical behavior of the liked ratee to external causes. Conversely, a disliked and unethical ratee would receive more negative ethical ratings because the rater may attribute unethical behavior of the disliked ratee to internal causes. The following proposition is offered:

Proposition 5: The influence of liking on ethical ratings will be mediated by attributional processing. 


\section{CONCLUSION}

In summary, in this paper, we developed a model of ethical performance appraisal using cognitive performance appraisal model. The model suggests that appraisal of ethical performance of employees is influenced by schematic, affective, and attributional processes. We offered a set of propositions that can be empirically tested. Ethical behavior could be manipulated by providing unethical, neutral and ethical critical incidents for each of the four ratees. Outcomes could be manipulated by providing performance outcome descriptions (successful or unsuccessful) for the four sales performance dimensions. Liking could be manipulated by providing briefs descriptions of sales person's social behavior. Attribution could be manipulated by suggesting that ethical behavior was influenced by external factors (e.g.., supervisory pressure) or internal factors (e.g., individual ethical beliefs) of employees. The scales for measuring variables in this study can be developed using the procedure demonstrated by Cardy and Selvarajan (2004b).

\section{AUTHOR INFORMATION}

T. T. Selvarajan is an Associate Professor of Management at the School of Business Administration, University of Houston-Victoria. His research interests are in performance appraisal and managing ethical behavior of employees in organizations.

Ron Sardessai is a Professor of Management at the School of Business Administration, University of HoustonVictoria. His research interests are in the area of business ethics.

\section{REFERENCES}

1. Akaah, I.P., \& Lund, D. 1994. The influence of personal and organizational values on marketing professionals' ethical behavior. Journal of Business Ethics, 13, 417-430.

2. Baker, E.M., \& Schuck, J.R. 1975. Use of signal detection theory to clarify problems of evaluating performance in industry. Organizational Behavior and Human Performance, 13, 307-317.

3. Baron, R.M., \& Kenny, D.A. (1986). The moderator-mediator variable distinction in social psychological research: Conceptual, strategic and statistical considerations. Journal of personality and Social Psychology, 51, 1173-1182

4. Baumhart, R.C. (1961).How ethical are businessmen? Harvard Business Review, 39, 6-9.

5. Berkowitz, L., \& Donnerstein, E. (1982). External validity is more than skin deep: Some answers to criticisms of laboratory experiments. American Psychologist, 61, 441-445.

6. Brady. F.N. (1990). Ethical managing: Rules and results. New York: Macmillan.

7. Brenner, S.N., \& Molander. 1977. Is the ethics of business changing? Harvard Business Review, 55, 57-71.

8. Bush, R.P., Bush, A.J., Ortinau, D J \& Hair, J.F. (1990). Developing a behavior-based scale to assess retail salesperson performance. Journal of Retailing, 66, 1, 119-136.

9. Cardy, R.L., \& Dobbins G.H. (1994). Performance appraisal: A consideration of alternative perspectives. Cincinnati, OH: South-Western.

10. Cardy, R.L., Anderson, J.S., \& Evans K.R. (1991). Judging performance: The impact of Behaviors, Outcomes and Trait Inferences. Paper presented at the 1991 Annual conference of the Society for Industrial and Organizational Psychology, Inc.

11. Cardy, R.L. and Kehoe, J.F. (1984). Rater selective attention ability and appraisal effectiveness: The effect of a cognitive style on the accuracy of differentiation among ratees. Journal of Applied Psychology, 69, 589-594.

12. Cardy, R.L., and Selvarajan, T. T. (2004a). Assessing ethical behavior: Development of a behaviorally anchored ethical performance appraisal scale. Paper presented at the Southwestern Academy of Management Meeting, Orlando, 2004.

13. Cardy, R.L. and Selvarajan, T.T. (2004b). Ethics and performance appraisal: Does success excuse all? Paper presented at the Southern Management Association Meeting, San Antonio, 2004.

14. Cleveland, J.N. (1991). Using hypothetical and actual applicants in assessing person-organization fit: A methodological note. Journal of Applied Social Psychology, 21, 1004-1011. 
15. Daniel, L.G., Elliott-Howard, F.E., \& Dufrene, D.D. (1997). The ethical issues rating scale: An instrument for measuring ethical orientation of college students toward various business practices. Educational and Psychological measurement, 57,3, 515-526.

16. DeCotiis, T.A., and Petit, A. (1978). The performance appraisal process: A model and some testable hypotheses. Academy of management review, 21, 635-646.

17. DeNisi, A.C., \& Stevens, G.E. (1981). Profiles of performance, performance evaluations and personnel decisions. Academy of Management Journal, 24, 592-602.

18. Froelich, K.S., \& Kottke, J.L. (1991). Measuring individual beliefs about organizational ethics. Educational and Psychological Measurement, 377-383.

19. Gatewood, R.D \& Carroll, A.B. (1991). Assessment of ethical performance of organization members: A conceptual framework. Academy of Management Review, 16 (4), 667-690.

20. Goldberg, L.R. (1990). An alternative "description of personality": The big-five structure. Journal of Personality and Social Psychology, 59, 1216-1229.

21. Gordon, M.E. (1970). The effect of correctness of the behavior observed on the accuracy of ratings. Organizational Behavior and Human Performance, 5, 366-377.

22. Hoffman, C., Mischel, W., \& Mazze, K. (1981). The role of purpose in the organization of information about behavior. Trait-based versus goal-based categories in person cognition. Journal of Personality and Social Psychology, 40, 211-225.

23. Krzystofiak, F., Cardy R.L., \& Newman, J. (1988). Implicit personality and performance appraisal: The influence of Trait Inferences on evaluations of behavior. Journal of Applied Psychology, 73, 515-521

24. Landy, F.J., and Farr, J.L. (1980). Performance ratings. Psychological Bulletin, 87: 72-107.

25. Larson, J.R., Lingle, J.H., \& Scerbo M.M. (1984). The impact of performance cues on leader behavior ratings: The role of selective information availability and probabilistic response bias. Organizational Behavior and Human Performance, 33, 323-349.

26. Lee, J.E. (1988). The effects of cognitive style on rating accuracy with an overall rating scale. Human Performance, 1: 261-271.

27. Lord, R.G. (1985). Accuracy in behavioral measurement: An alternative definition based on rater's cognitive schema and signal detection theory. Journal of Applied Psychology, 70, 66-71.

28. Lucas, G.H. Jr. (1985). The relationship between job attitudes, personal characteristics and job outcomes: A study of retail store managers. Journal of Retailing, 61, 35-62.

29. Neisser, U. (1967). Cognitive Psychology. Englewood Cliffs, NJ: Prentice Hall.

30. Newstrom, J. W., \& Ruch, W.A . (1975). The ethics of management and management of ethics, MSU Business Topics, 31,

31. Snodgrass, J.G., \& Corwin, J. (1988). Pragmatics of measuring recognition memory: Applications to dementia and amnesia. Journal of Experimental Psychology: General, 117, 34-50.

32. Sulsky, L.M., \& Day, D.V. (1992). Frame of reference training and cognitive categorization: An empirical investigation of rater memory issues. Journal of Applied Psychology, 77, 501-510.

33. Trevino, L.K. (1986). Ethical decision making in organizations: A person-situation interactionist model. Academy of Management Review, 11 (3), 601-617.

34. Trevino, L.K ., \& Youngblood, S.A. (1990). Bad apples in bad barrels: A causal analysis of ethical decision-making behavior. Journal of Applied Psychology, 75, 378-385. 